\title{
Advanced Hydrogels for the Controlled Delivery of Insulin
}

\author{
Shazia Mansoor, Pierre P. D. Kondiah (1) and Yahya E. Choonara * (1) \\ Wits Advanced Drug Delivery Platform Research Unit, Department of Pharmacy and Pharmacology, \\ School of Therapeutic Sciences, Faculty of Health Sciences, University of the Witwatersrand, 7 York Road, \\ Parktown, Johannesburg 2193, South Africa; 707825@students.wits.ac.za (S.M.); \\ pierre.kondiah@wits.ac.za (P.P.D.K.) \\ * Correspondence: Yahya.Choonara@wits.ac.za; Tel.: +27-11-717-2052
}

Citation: Mansoor, S.; Kondiah, P.P.D.; Choonara, Y.E. Advanced Hydrogels for the Controlled Delivery of Insulin. Pharmaceutics 2021, 13, 2113. https://doi.org/ 10.3390/pharmaceutics13122113

Academic Editor: Marta

González-Álvarez

Received: 14 October 2021

Accepted: 19 November 2021

Published: 8 December 2021

Publisher's Note: MDPI stays neutral with regard to jurisdictional claims in published maps and institutional affiliations.

Copyright: (c) 2021 by the authors. Licensee MDPI, Basel, Switzerland. This article is an open access article distributed under the terms and conditions of the Creative Commons Attribution (CC BY) license (https:// creativecommons.org/licenses/by/ $4.0 /)$.

\begin{abstract}
Insulin is a peptide hormone that is key to regulating physiological glucose levels. Its molecular size and susceptibility to conformational change under physiological $\mathrm{pH}$ make it challenging to orally administer insulin in diabetes. The most effective route for insulin delivery remains daily injection. Unfortunately, this results in poor patient compliance and increasing the risk of microand macro-vascular complications and thus rising morbidity and mortality rates in diabetics. The use of 3D hydrogels has been used with much interest for various biomedical applications. Hydrogels can mimic the extracellular matrix (ECM) and retain large quantities of water with tunable properties, which renders them suitable for administering a wide range of sensitive therapeutics. Several studies have demonstrated the fixation of insulin within the structural mesh of hydrogels as a bio-scaffold for the controlled delivery of insulin. This review provides a concise incursion into recent developments for the safe and effective controlled delivery of insulin using advanced hydrogel platforms with a special focus on sustained release injectable formulations. Various hydrogel platforms in terms of their methods of synthesis, properties, and unique features such as stimuli responsiveness for the treatment of Type 1 diabetes mellitus are critically appraised. Key criteria for classifying hydrogels are also outlined together with future trends in the field.
\end{abstract}

Keywords: hydrogels; injectable hydrogels; stimuli responsive systems; controlled release; insulin administration

\section{Introduction}

$\beta$-cells located within the pancreatic islets of Langerhans produce insulin (a peptide hormone) that regulates physiological glucose homeostasis. However, in diabetic patients, hormone functioning is impaired, resulting in uncontrolled hyperglycemia [1]. The autoimmune destruction of pancreatic $\beta$-cells leads to type 1 diabetes (T1D), in which there is a total lack of insulin secretion. Exogenous insulin remains the most effective form of treatment for the management of T1D, often requiring multiple daily injections. This often results in poor patient compliance, resulting in increasing mortality and hospitalization rates [2].

To overcome the barriers facing insulin administration, insulin analogues and innovative delivery systems have been developed to manipulate the pharmacokinetic profile of various insulin analogues. Orally administered insulin is desirable, but the poor GIT stability and large molecular weight (size) limit the possibility of oral administration of insulin to reach sufficient bioavailability [3]. Thus, injectable insulin remains the gold standard for T1D therapy, and much research has concentrated on the design of injectable hydrogel-based systems for the controlled (sustained) release of insulin [4]. Injectable hydrogels undergo a sol-gel transition and are typically administered in the sol state using a syringe with transitioning to a gel in vivo [5]. Insulin can be encapsulated within nanoparticles (NPs) fixated in the hydrogel before injecting. Once sol-gel transitioning occurs, the insulin is entrapped within the hydrogel network to provide spatio-temporal 
release over time [6]. This strategy allows for fewer injections to be administered with a reduced side effects profile and an improved patient compliance.

Hydrogels are 3D polymeric matrices and take on a solid matrix structure known as the first phase (Figure 1A) [7]. When encountering fluid, the molecules penetrate and diffuse into the matrix, causing the networked chemical structure to relax and resulting in a barrier-like 3D meshed structure filled with fluid in the interstitial space (Figure 1B) [8]. The hydrogel structure can impart an elastic force that allows hydrogels to expand and contract for added structural stability. The ionic phase comprises ionizable groups that are bound to the polymer chains and allow for functionalization of the hydrogel system [9]. Biodegradable, natural, and synthetic polymers (or combinations of these) are frequently used to synthesis hydrogels. Hydrogels that can retain considerable amounts of water have hydrophilic functional groups on their polymer backbones such as $-\mathrm{OH},-\mathrm{NH}_{2}$, or $-\mathrm{COOH}[6,10]$. Water retention (swelling) results in desirable consistency and interfacial tension with biological fluids [7,11]. Figure 1B depicts the molecular structure of a typical hydrogel and its interactions with water. Interestingly, the widespread use of hydrogels in biomedical applications is largely due to their morphology being similar to the extracellular matrix (ECM) of the body $[7,8]$.

A

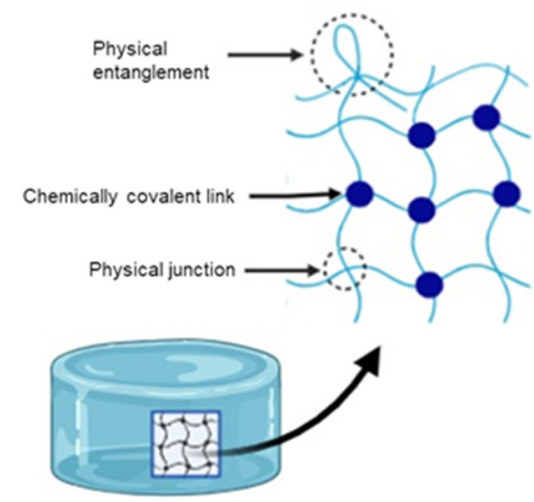

B

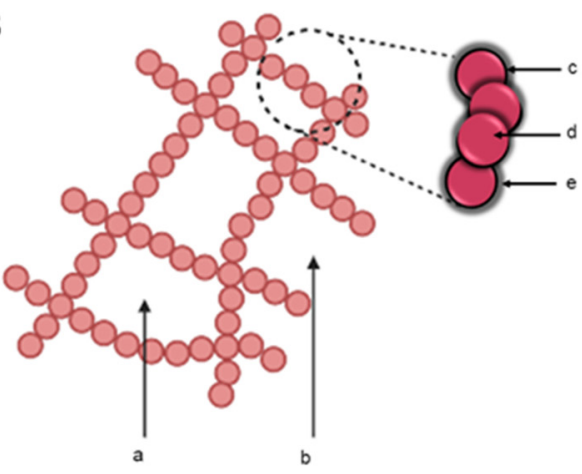

Figure 1. (A) Annotated illustration showing the mesh structure of a hydrogel. Physical and chemical points of crosslinking are illustrated along with physical entanglement of the structure. (B) Illustration depicting the morphology of a hydrogel network. (a) Interstitial water, (b) Free water, (c) Bound water, (d) Hydrogel monomer represented by spheres, (e) Semi-bound water. Adapted from [9,10], published by Elsevier, 2015 and Taylor and Francis, 2015.

Hydrogels do not impact metabolism and are designed to be bio-orthogonal in vivo. They are biocompatible and have a porous structure and tunable biodegradability [8]. The pore size determines the mesh size, which can be controlled to achieve the sustained delivery of bioactives [12]. Thus, the rate of bioactive delivery is dependent on the swelling and stimuli responsiveness of the hydrogel. Stimuli-responsive hydrogels can respond to triggers such as physiological temperature and $\mathrm{pH}$. Injectable hydrogels, which are a specialized class of hydrogels, can be administered subcutaneously or at the target site to avoid presystemic metabolism. The nature of stimuli-responsive injectable hydrogels to transition into a viscoelastic gel once injected can serve as a depot (reservoir) for controlled insulin release [6].

Hydrogels are classified widely based on the source of polymer/s employed, ionic charge of bound group/s, type of crosslinking (physical or chemical), stimuli responsiveness, synthesis methods, biodegradability, and structure (Figure 2) [9]. The utilization of hydrogel platforms for the advanced delivery of therapeutic proteins and peptides has revolutionized therapeutics and is an exponentially growing class of treatment. 


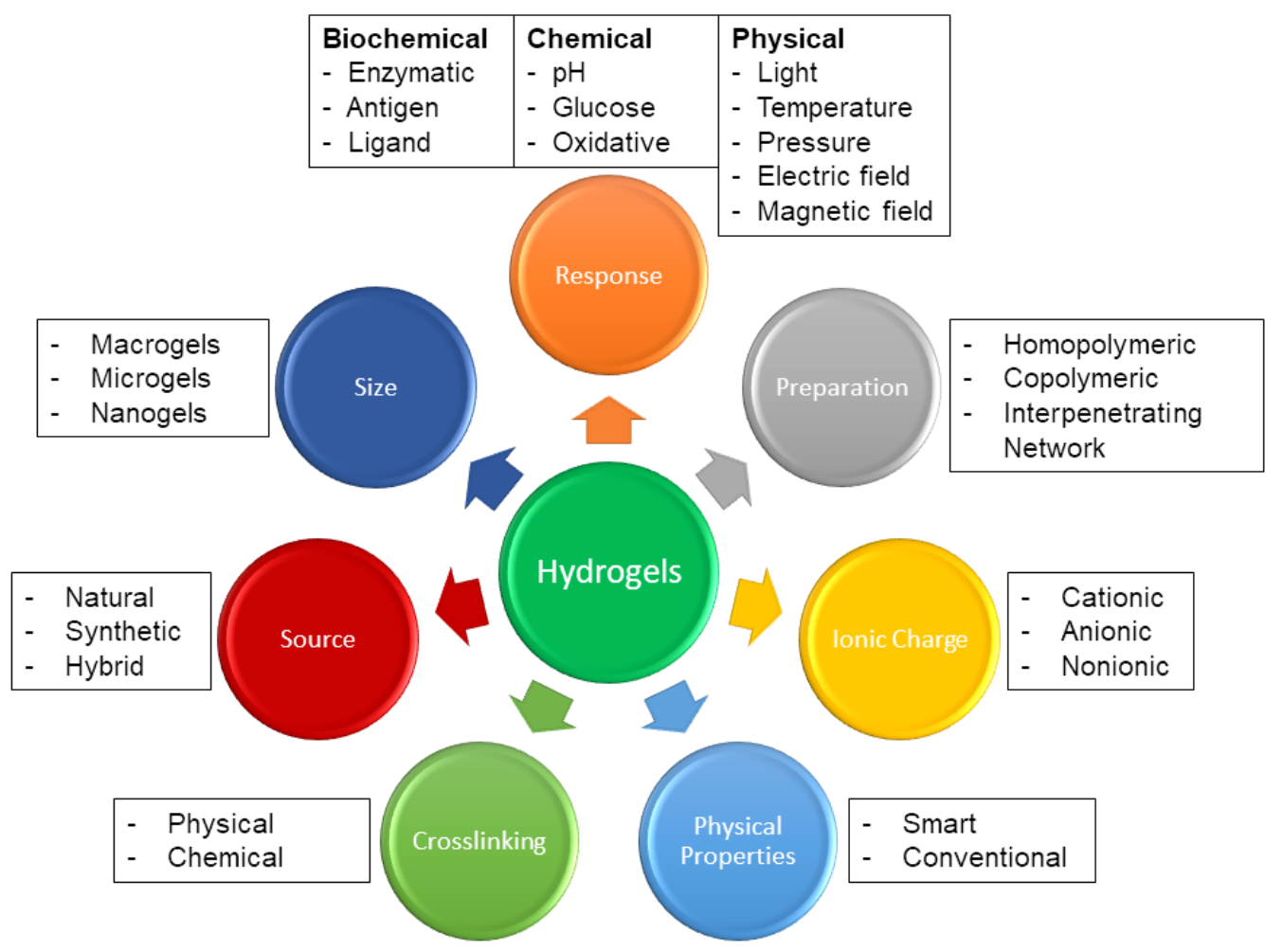

Figure 2. An illustration of how hydrogels can be classified based on factors such as the source and preparation of polymers employed, the charge of hydrogels, type of crosslinking, stimuli responsiveness, and physical properties. Adapted with permission from [9]; Published by Elsevier, 2015.

Therefore, this review provides a concise incursion into recent developments for the safe and effective controlled delivery of insulin using advanced hydrogel platforms with a special focus on the sustained release injectable formulations. Various hydrogel platforms in terms of their methods of synthesis, properties, and unique features such as stimuli responsiveness for the treatment of T1D are critically appraised. Key criteria for classifying hydrogels are also outlined together with future trends in the field.

\section{Biocompatibility and Biodegradability of Hydrogels as Insulin Carriers}

\subsection{Biocompatibility}

Insulin has a quaternary structure made up of A and B chains and is preserved via weak non-covalent bonds. First-pass metabolism usually occurs when insulin is administered orally. Insulin enters the portal vein and travels via the small intestine, colon, and spleen to reach the liver, where it may be metabolized, before entering the systemic circulation. This leads to a lower drug bioavailability $[13,14]$. The weak covalent bonds of insulin are affected by the $\mathrm{pH}$ of the gastrointestinal tract (GIT) and stomach and are degraded physically and chemically. Additionally, insulin is a macromolecule resulting in a reduced drug bioavailability $[15,16]$. To improve the bioavailability of insulin, researchers have incorporated the drug into the mesh structure of the hydrogel system. Thus, the peptide is protected by the hydrogel network and is injected to avoid the GIT for protection from physiological destabilization and degradation. Scientists employ specific polymers that have tunable properties in hydrogel synthesis so as to circumvent a toxic or immune response in the body $[16,17]$, thus rendering the insulin encapsulated hydrogel: a biocompatible drug delivery system (DDS).

\subsection{Biodegradability}

Formulated hydrogels are designed so that they are able to self-degrade, allowing for low or non-toxicity build-up over time [8]. This means that the hydrogel DDS synthesized 
can be metabolized into non-toxic by-products or expelled via glomerular filtration [18]. Hydrogels have the advantage of biodegradability in comparison to other biomaterial platforms due to the polymers employed [8]. Furthermore, labile bonds (Table 1) that have been introduced into the hydrogel system, as either the cross-linker or in the network backbone, are cleaved along with unstable linkages. This is accomplished primarily via hydrolysis or under physiological conditions, either chemically or enzymatically [18]. When a biodegradable hydrogel has been loaded with a drug, the DDS has an added advantage of sustained release over a significant period of time, improving patient compliance as well as reducing side effects and morbidity rates [19]. Overall, functional groups such as amines, esters, anhydrides, phosphazenes, and phosphate esters, which are found in the polymeric and biomolecule components, can influence hydrogel degradability [20,21].

The use of carbohydrate polymers, which are biodegradable, enables controlled hydrogel degradation while releasing insulin in a sustained manner. Hydrogels made from polysaccharides i.e., carbohydrates, have shown substantial progress in targeted insulin delivery due to their natural characteristics such as pore size, mesh structure, sustainability, and stimuli responsiveness to external factors [17].

Table 1. Describing different labile bonds present in hydrogels, including their functional groups and chemical structures, for the release of therapeutic agents. Adapted with permission from [20]; Published by MDPI, 2019.

Linker Type


Table 1. Cont.

\begin{tabular}{ccc}
\hline Linker Type & Degradation Conditions & References \\
\hline $\begin{array}{c}\text { Linker based on disulfide or } \\
\text { diselenide bridges }\end{array}$ & $\begin{array}{c}\text { Hydrolysis in the presence of } \\
\text { GSH carboxyethylphosphine } \\
\text { tris (TCEP), and dithiothreitol } \\
\text { (DTT) }\end{array}$ \\
[27-29] \\
Hydrolysis in the presence of \\
phosphatase or phospholipase \\
enzyme
\end{tabular}

Carbohydrate polymers may also be modified to produce synthetic polymers, such as methylcellulose or carboxymethyl cellulose (CMC), for use in hydrogel preparation, as was done by Gao et al. The team of researchers developed CMC/polyacrylic acid (PAA) hydrogels for orally administered insulin $(60 \mathrm{IU} / \mathrm{kg})$. In vivo studies carried out in diabetic rats demonstrated that fasting plasma glucose levels decreased by $72.4 \%$ within $6 \mathrm{~h}$ after administration. Additionally, the relative bioavailability of the orally administered insulin loaded hydrogel $(6.59 \%)$ was $10 \times$ greater than of free insulin solution $(>0.5 \%)$ [31].

In 2020, researchers further used carbohydrate polymers for insulin delivery. They developed a $\mathrm{pH}$-sensitive carboxymethyl $\beta$-cyclodextrin grafted carboxymethyl chitosan hydrogel. Using EDC/NHS as coupling agents, the hydrogel was synthesized for oral insulin administration. Cell studies showed non-toxicity, while in vivo studies demonstrated a lowered blood glucose level (BGL) that was significant and sustained (6-12 h) [32].

The use of synthetic polymers for the oral administration of insulin shows promise. However, shortfalls such as a lack of sustained drug release and increasing drug release profiles in response to physiological $\mathrm{pH}$ levels remain obstacles.

\section{Hydrogel Synthesis, Morphology, and Properties}

\subsection{Physical and Chemical Crosslinking}

As hydrogels are networks or matrices of polymers, crosslinking between the polymers is required to prevent the dissolution of the network before use [18]. The type of crosslinking used in hydrogel synthesis is an important factor that affects hydrogel properties and must be determined in accordance with its desired application [6]. Polymeric crosslinking can be largely classed as either physical or chemical. When hydrogels swell, the crosslinking of polymers assists in maintaining the 3D conformation of the gel [33]. Crosslinking may occur; in vitro i.e., during hydrogel synthesis, or in vivo (in situ) i.e., post administration of the hydrogel [34]. Hydrogels possess physical domain junctions under physical crosslinking, and a non-permanent self-assembly takes place. Chemical crosslinking takes place covalently between the hydrogel polymer chains [9]. As crosslinking is introduced, the hydrogel exhibits viscoelastic or purely elastic properties. The type of crosslinking should be determined by the polymerization technique employed in the formulation as well as the desired features of the hydrogel system. In terms of toxicity occurring during chemical crosslinking, the crosslinker used in the hydrogel's synthesis can be removed from the system before usage by dialysis or any other suitable method [18].

Dual-network hydrogels may be formed because of electrostatic interactions and are synthesized via a combination of physical and chemical crosslinking. These hydrogels have been developed to overcome the shortfalls of using only physical or chemical crosslinking. 
These dual-network hydrogels have a higher swelling capacity over a wider $\mathrm{pH}$ range and are more sensitive to $\mathrm{pH}$ fluctuations than chemically cross-linked hydrogels [9].

\subsection{Morphological Components}

A hydrogel's morphology is determined primarily by the amount of water it can retain and the crosslinking process used. Depending on the concentration of hydrophilic groups occurring on the polymer chains, hydrogels may retain different quantities of $\mathrm{H}_{2} \mathrm{O}$. The amount of water retained by the hydrogel varies from a fraction to a $1000 \times$ its weight [8] The swelling ability of hydrogels is critical for their usage in biomedical applications. This is due to the equilibrium swelling ratio to the ratio of the weight of swollen hydrogel divided by the dry hydrogel, which affects multiple parameters. These parameters include the solute diffusion coefficient, mechanical properties, surface wettability, and mobility of the hydrogel. The molecular weight (MW) and charge of the polymer/s employed in hydrogel synthesis regulate the physical properties of swollen hydrogels. Moreover, the density of crosslinking and physical associations also plays a role in the physical characteristics of the swollen hydrogel. Furthermore, the amount of bonding between polymeric chains is defined by each of these parameters. The integrity of encapsulated therapeutic agents is dependent on these properties as protection from mechanical deformation at the targeted drug delivery site $[35,36]$.

\subsection{Molecular Characteristics \\ 3.3.1. Viscoelasticity}

As polymer chains crosslink, the hydrogel network exhibits viscoelastic and/or purely elastic behavior [18]. However, before gelation of the hydrogel matrix, the viscosity must be low enough to permit a homogenous dispersion of medication within the gel. After injecting of the hydrogel system, moderate gelation conditions must exist in order to minimize cytotoxicity and sufficiently encapsulate pharmaceutical drugs and cells to be administered.

As a result, the viscosity of a polymer solution needs to be taken into account to achieve a hydrogel solution that is easily injectable, thereby allowing for a non-surgical procedure that is minimally invasive [6].

\subsubsection{Pore Size}

The porosity of hydrogels refers to a highly intertwined and organized mesh structure that makes up the hydrogel matrix. This network may exist at the micro- or nano-scale depending on the use of the hydrogel [6]. The porosity of a hydrogel is regulated and dependent upon the crosslinking density of the matrix network. The porous morphology provides a matrix for drug loading while also protecting the drug from any physiologically damaging environments [8]. These porous matrices are important for improved drug release as well as for the transport of nutrients for cell growth if need be [6]. The porous network may vary in its distribution, size, and interconnections while making up the hydrogel structure. 'Tortuosity' may be used to describe these three characteristics, and this along with the hydrogel composition and amount of crosslinking affects the hydrogel tortuosity [37].

A hydrogel's porous network can be categorized as nonporous, microporous, or superporous as related to the pore size between the polymer networks. The porosity of the gel has a significant impact on its swelling behavior. Nonporous hydrogel diffusion is the only way to achieve water swelling in a medium. Microporous hydrogels have very small pores ranging from a few microns to a few hundred microns, which can be investigated using SEM or other imaging technology. Accordingly, there is an increased diffusion rate of swelling in microporous hydrogels as water uptake takes place via diffusion and/or leaching through pores. Specifically formulated superporous hydrogels have concentrated, larger pore sizes, thereby allowing for higher swelling rates over a shorter period. The 
commercial applications for these types of hydrogels include superabsorbent responsive biomedical devices, agriculture, and others [10].

The pore size of the hydrogel to be synthesized must be chosen with care, taking into consideration the diffusion and swelling rates desired. The larger and more concentrated the pore size, the faster the swelling mechanism [10].

\subsubsection{Swelling and Drug Release}

Due to the hydrophilic chains in the hydrogel network, the hydrogel has the ability to take up water and swell [11]. The uptake of water into the hydrogel can be controlled by stimuli responsiveness [3]. The ability to retain water is very important, as the hydrogel mimics human tissue and thus is considered favorably in a host of biomedical drug delivery platforms. Due to crosslinking, hydrogels are able to maintain their 3D conformation during swelling [9]. Stimuli-responsive swelling is synonymous with the control of diffusion into and out of the hydrogel network, which in turn allows for spatial and temporal control over drug release, as seen in Figure 3 below [3]. The mechanism of hydrogel swelling is based upon three differing concepts: The Differentiation Theory, The Mechanism of Gelation, and The Rubber Elasticity Theory. The Flory-Huggins Theory discusses how temperature and polymer- $\mathrm{H}_{2} \mathrm{O}$ interactions affect the swelling magnitude of a hydrogel. The release rate of encapsulated drugs is an important factor to determine when formulating the hydrogel. The release rate of drugs is dependent largely on the diffusion coefficient of the pharmaceutical agent through the gel structure [8,38]. Zero-order drug kinetics is the golden standard for release rates.

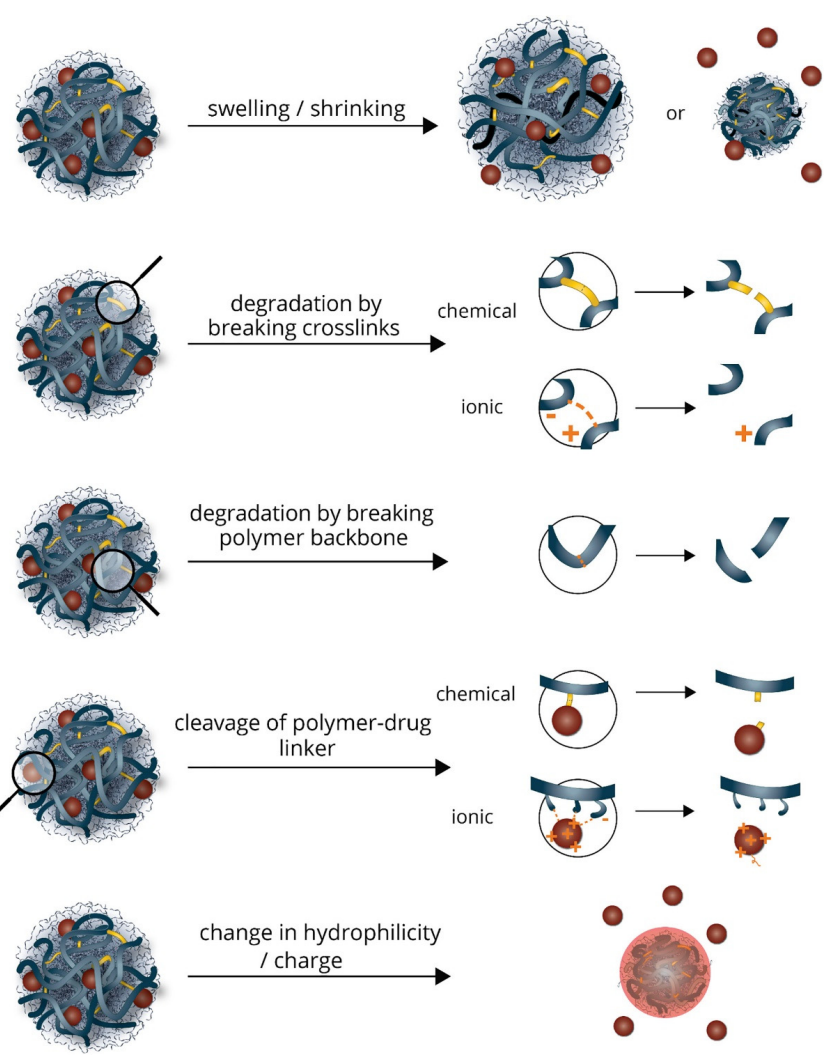

Figure 3. Illustration of the varied stimuli-responsive swelling mechanisms occurring within hydrogels. Adapted with permission from [39]; Published by Elsevier, 2019.

\section{Modified Hydrogel Platforms for Controlled Insulin Delivery}

\subsection{Injectable Hydrogel Systems for the Regulated Delivery of Insulin}

There have been numerous studies conducted on injectable hydrogels as insulin carriers for the management of T1D. 
Xue developed an injectable shear-thinning hydrogel to encapsulate and modulate the release of insulin. A cyclodextrin-adamantane supramolecular hydrogel was used to induce the spontaneous crosslinking of hyaluronic acid (HA) and showed that the hydrogels formed an injectable depot in vivo. It was also shown that insulin release was controlled in vitro and in vivo by altering the molecular mass and concentration of the polymers. In addition, the hydrogels could be blended with protein-based insulin particles to extend the release rate in vivo and in vitro over 30 days [40].

Dong et al. produced a stimuli-responsive injectable hydrogel based on the complexation of glucose and boronic acid in which the ratio of boronic acid to glucose functional groups was paramount for the synthesis. Polymers with 10-60\% boronic acid and the rest glucose-modified were favored. The hydrogel showed shear thinning and self-healing to rebound from a shear-induced flow to a gel state instantaneously and showed glucoseresponsive in vitro release [41].

A novel glucose-responsive insulin encapsulated injectable hydrogel platform was synthesized by Zhao et al. The hybrid formulation combined phenylboronic acid-poly (lactic-co-glycolic acid) (PBA-PLGA) modified microparticles with a HA-dopamine hydrogel. The hydrogel was developed with shear-thinning behavior to allow for injection and tissue-adhesive properties and demonstrated rapid glucose responsiveness at physiological $\mathrm{pH}$. When injected once subcutaneously in vivo into STZ-induced diabetic mice, blood glucose was sustained for up to 2 weeks [42].

Other research groups have developed a trehalose-based injectable hydrogel for insulin to preserve the structure of insulin when delivered and protect it from high temperature. A polymer containing trehalose side chains with a PBA end-functionalization polyethylene glycol (PEG) was employed. Boronate ester crosslinks with the PEG-boronic acid via the $-\mathrm{OH}$ groups on the trehalose side chain formed the hydrogel. The addition of glucose as a stronger binder to boronic acid caused stimuli-responsive insulin release. Results showed that trehalose-based polymers and boronic acid cross-linkers can be used to rapidly synthesize injectable hydrogels. The degradation rate of the hydrogel was accelerated by increased glucose content in the buffer inducing rapid insulin release. In addition, the trehalose hydrogel proved to be an excellent heat stress protector for insulin. Since protein-based therapies must be kept at specific temperatures to maintain activity, trehalose hydrogels could potentially be used without the need for specialized refrigeration. Within $1 \mathrm{~min}$, the mixture thickened, and within $5 \mathrm{~min}$, a gel was formed, making it suitable for injection [43].

An injectable silk fibroin hydrogel (iSFH) has also been developed by Maity et al. to provide a prolonged release of insulin. Ethylene-and triethylene-glycol was added to the silk fibroin protein, forming an injectable hydrogel within $50 \mathrm{~min}$. The desired encapsulation of active insulin was demonstrated via SEM in which the hydrogel showed a mesoporous structure. T1D Wistar rats were injected subcutaneously with the insulin-iSFH system, resulting in a regulated release of insulin and maintenance of normoglycemia for up to 4 days. The biodegradable and biocompatible nature of iSFH has increased interest in using it as a potential system to regulate and prolong the delivery of insulin, thus achieving homeostatic blood glucose levels [44].

Injectable hydrogels are able to deliver targeted drug delivery with sustained release while maintaining physiological BGLs. As demonstrated above, the injectable systems are often stimuli responsive, forming a depot within the body, virtually mimicking the pancreas [6]. These injectable hydrogels also do not have the expense of 3D printing. However, for a system that is completely biomimetic, more research needs to be done with regard to incorporating islet stem cells into the hydrogel systems for $\beta$-cell regeneration [35]. In addition to injectable hydrogels, microgels and nanogels are also being studied extensively (Table 2). 
Table 2. Micro- and nano-hydrogel systems for insulin delivery. Including polymers utilized, sustained release time, and whether they have been tested in cell or animal models.

\begin{tabular}{|c|c|c|c|c|c|}
\hline System Employed & Polymers Utilized & $\begin{array}{c}\text { Insulin } \\
\text { Encapsulation } \\
\text { Efficiency } \\
\text { (EE)/Loading } \\
\text { Capacity (LC) (\%) }\end{array}$ & $\begin{array}{c}\text { Insulin Release } \\
\text { Time }\end{array}$ & $\begin{array}{l}\text { In Vitro or In } \\
\text { Vivo Studies } \\
\text { Carried Out }\end{array}$ & References \\
\hline $\begin{array}{l}\text { Nanoparticles within } \\
\text { microgel }\end{array}$ & $\begin{array}{l}\text {-Alginate } \\
\text {-Acetylated dextran }\end{array}$ & $\begin{array}{l}39 \%-\mathrm{EE} \\
6.5 \%-\mathrm{LC}\end{array}$ & $\begin{array}{c}22 \text { days ( } 2 \text { doses) } \\
\text { in vivo }\end{array}$ & $\begin{array}{l}\text { In vitro and } \\
\text { in vivo studies } \\
\text { carried out }\end{array}$ & {$[45]$} \\
\hline $\begin{array}{c}\text { Microgel } \\
\text { encapsulated } \\
\text { microspheres }\end{array}$ & -CHC (Chitosan) & $62.96 \pm 0.68 \%-\mathrm{EE}$ & 7 days in vitro & In vitro studies & [46] \\
\hline $\begin{array}{l}\text { Ultrasound triggered } \\
\text { nanocapsules within } \\
\text { microgel }\end{array}$ & $\begin{array}{l}\text {-PLGA } \\
\text {-CHC }\end{array}$ & $\begin{array}{l}71.3 \pm 1.8 \%-\mathrm{EE} \\
11.9 \pm 0.6 \%-\mathrm{LC}\end{array}$ & $\begin{array}{l}10 \text { days in vitro } \\
7 \text { days in vivo }\end{array}$ & $\begin{array}{l}\text { In vitro and } \\
\text { in vivo studies } \\
\text { carried out }\end{array}$ & [47] \\
\hline $\begin{array}{c}\text { Self-assembled } \\
\text { nanoparticles in gel } \\
\text { (nanogel) }\end{array}$ & $\begin{array}{c}\text {-Carboxymethyl- } \\
\text { hexanoyl } \\
\text { CHC }\end{array}$ & $\begin{array}{l}\text { Insulin loaded } \\
5 \mathrm{mg} / \mathrm{mL}\end{array}$ & 10 days in vivo & $\begin{array}{l}\text { In vitro and } \\
\text { in vivo studies } \\
\text { carried out }\end{array}$ & [48] \\
\hline $\begin{array}{l}\text { Monodispersed } \\
\text { nanogels }\end{array}$ & $\begin{array}{c}\text {-Poly }(\mathrm{N}- \\
\text { isopropylacrylamide }) \\
\text {-Dextran } \\
\text {-Poly(3- } \\
\text { acrylamidophenylboronic } \\
\text { acid) }\end{array}$ & $\begin{array}{l}80.6 \%-\mathrm{EE} \\
16.2 \%-\mathrm{LC}\end{array}$ & $2 \mathrm{~h}$ in vivo & $\begin{array}{l}\text { In vitro and } \\
\text { in vivo studies } \\
\text { carried out }\end{array}$ & [49] \\
\hline $\begin{array}{c}\text { Double-layered } \\
\text { nanogel }\end{array}$ & $\begin{array}{c}\text {-Glycol CHC } \\
\text {-Sodium alginate poly } \\
\text { (L-glutmate-co-N-3-L- } \\
\text { glutamylphenylboronic } \\
\text { acid) }\end{array}$ & $71 \pm 3.5 \%-\mathrm{LC}$ & $3 \mathrm{~h}$ in vivo & $\begin{array}{l}\text { In vitro and } \\
\text { in vivo studies } \\
\text { carried out. }\end{array}$ & {$[50]$} \\
\hline
\end{tabular}

\subsection{The Use of Microgels for the Controlled Delivery of Insulin}

Microgels are 3D microscopic intramolecular cross-linked gels that are macromolecules with a modifiable shape and size range of $1 \mathrm{~nm}$ to $10 \mu \mathrm{m}$ [51]. Microgels are distinct in that they are injectable and offer a highly tunable, modular microstructure while retaining the bioactive encapsulating properties and biocompatibility of the hydrogel analogue. Microgels are extensively tunable and demonstrated their relevance in a wide range of tissue engineering applications [52]. They can be synthesized via minor modifications to established polymerization protocols and can be designed to have pendant functional groups capable of interacting with metal ions, which are progenitors of metal nanoclusters. Thus, microgels can be loaded with metal precursors, which then are reduced inside the microgel to yield metal particles [53]. The colloidal stability in conjunction with a Young's modulus of 0.1-100 kPa allows for the excellent loading and release of encapsulated bioactives within the microgel network [54].

Volpatti et al. synthesized a microgel encapsulating nanoparticles for specialized glucose-responsive insulin release. Alginate was cross-linked with divalent cations to form the microgel platform, and the nanoparticles were synthesized using acetylateddextran, glucose oxidase, and catalase before loading insulin. The alginate-based microgel demonstrated the ability to maintain glucose-responsive insulin release in preclinical testing with homeostatic blood glucose levels achieved using two doses over a period of 21 days in vivo [45].

Researchers also developed a microgel containing insulin-loaded chitosan (CHC) microspheres (Figure 4). By transferring an aqueous $\mathrm{CHC}$ /acetic acid solution loaded with insulin via the uniform porous glass membrane into a paraffin/petroleum ether combination comprising hexaglycerin penta-ester (PO-500) emulsifier, a stable $\mathrm{W} / \mathrm{O}$ emulsion with a consistent particle size was produced. Ionic crosslinking with tripolyphosphate 
(TPP) added dropwise to the emulsion generated a microgel. Chemical crosslinking with glutaraldehyde was undertaken to harden the homogenous droplets of $\mathrm{CHC}$. The microspheres were solidified to form a gel by ionic crosslinking between TPP and CHC, and the state of solidification was adjusted in vitro based on encapsulation efficiency, microsphere shape, drug activity, and the insulin release profile. The final insulin-loaded microgel was evenly sized and ranged in diameter from 4 to $15 \mathrm{~mm}$ in diameter [46].

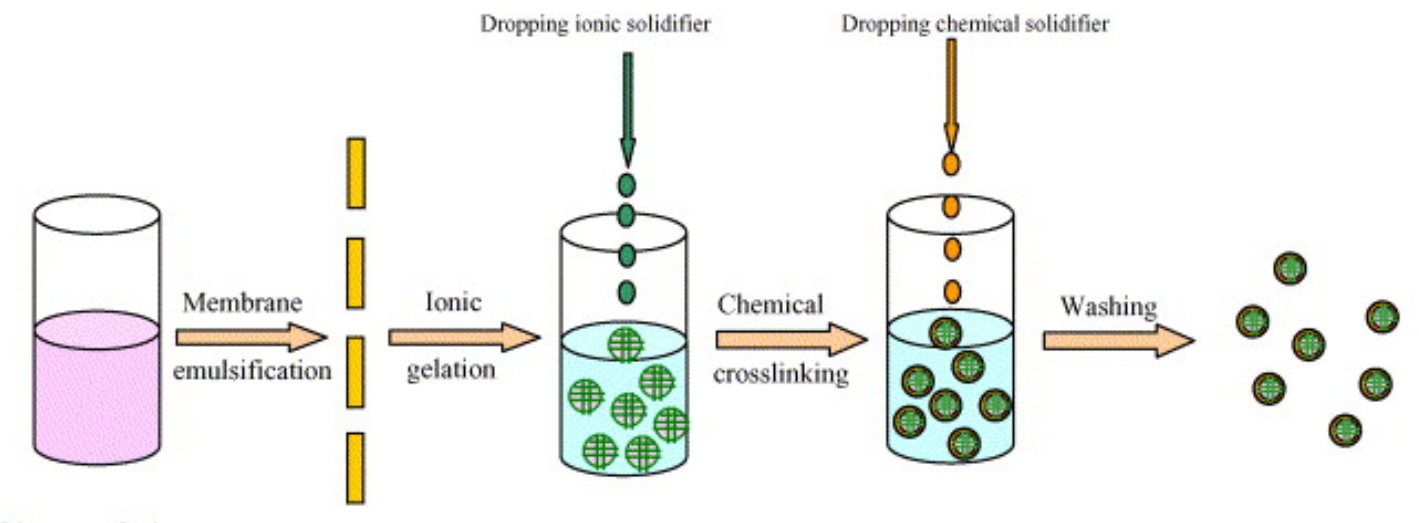

Chitosan solution

Chitosan microspheres

Figure 4. Diagram showing the synthesis of insulin-loaded CHC microspheres via ionic crosslinking to produce microgels in conjunction with chemical crosslinking. Adapted with permission from [46]; Published by Elsevier, 2006.

Di et al. developed insulin-encapsulated PLGA nanocapsules loaded (via passive diffusion) within $\mathrm{CHC}$ microgels. The ultrasound-triggered system allowed for a pulsatile release of insulin via the microgel, allowing for both a rapid acting and sustained insulin release over time. Insulin was promptly released after ultrasound treatment to control blood glucose levels (Figure 5). In in vivo studies in T1D mice (subcutaneously injected) with the insulin-loaded microgel (250-300 $\mu \mathrm{g} / \mathrm{mL}$ per mouse) and thereafter, the application of ultrasound demonstrated the successful maintenance of blood glucose levels for 7 days when activated by $30 \mathrm{~s}$ of ultrasound administration [47].

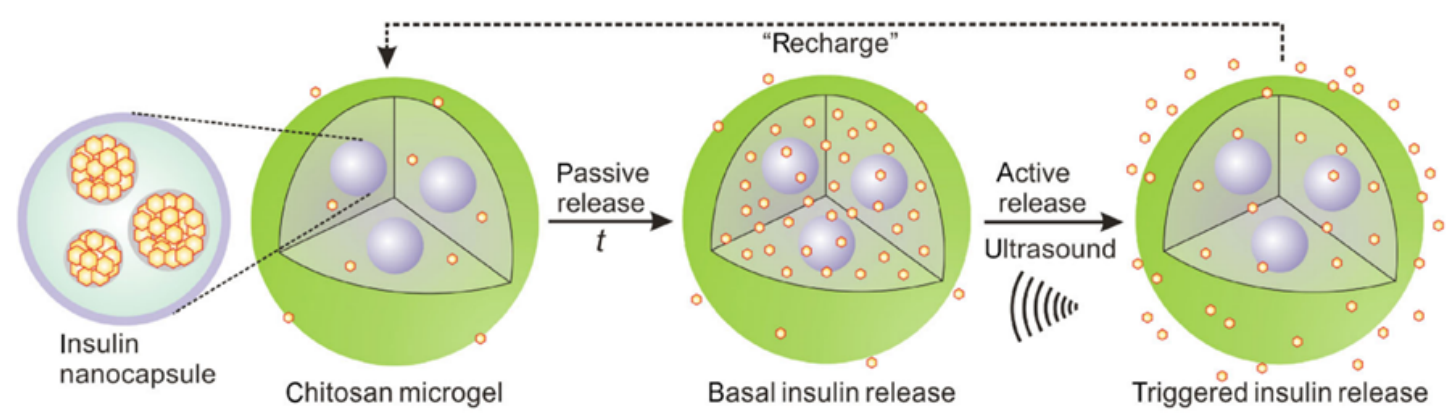

Figure 5. Schematic diagram of a CHC microgel encapsulating insulin-loaded PLGA nanocapsules. The loaded insulin has a passive and active basal drug release but is triggered and dependent on US. Adapted from [47] (Creative Common License); Published by Springer, 2017.

\subsection{The Use of Nanogels for the Controlled Delivery of Insulin}

Similar to microgels, nanogels have a swellable 3D structure but at the nanoscale dimension (10-1000 nm). Nanogels are formed by physical or chemical crosslinking of natural or synthetic polymers and have a significant capacity to retain water without dissolving due to the presence of hydrophilic or amphiphilic macromolecular chains. Nanogels have water content that corresponds with the fluid-like transport characteristics of physiologically active compounds that are significantly lower than the gel pore 
size $[55,56]$. Stimuli-responsive nanogels specifically have great potential for application in controlling the delivery of bioactives due to their size, tuneability, and biocompatibility [39]. Nanogels are also known as hydrogel nanoparticles and act as multifunctional complexes with adaptable properties. Nanogel-based formulations are useful in nanomedicine [55].

An insulin-loaded injectable nanogel was developed by Chou et al. using selfassembled nanoparticles comprising carboxymethyl-hexanoyl $\mathrm{CHC}$. The researchers combined carboxymethyl-hexanoyl CHC nanoparticles with $\beta$-glycerophosphate, which is a natural compound found within the body. It intercalates with $\mathrm{CHC}$ and acts as a catalyst, allowing the system to form a matrix network that can undergo gel-sol transition under high temperatures [57]. Additionally, researchers incorporated lysozyme to the system to regulate insulin release and nanogel biodegradation (Figure 6). The presence of active lysozymes on $\mathrm{CHC}$ was verified by in vitro assays and showed that the quantity of lysozymes in the nanogel affected the rate of insulin release. Cytotoxicity results revealed that the nanogel was biocompatible, while animal studies showed a single injection maintained fasting blood glucose for 10 days. The insulin-loaded CHC-lysozyme nanogel showed much promise as an injectable gel for sustained insulin delivery with the ability to control basal insulin levels over a prolonged period [48].

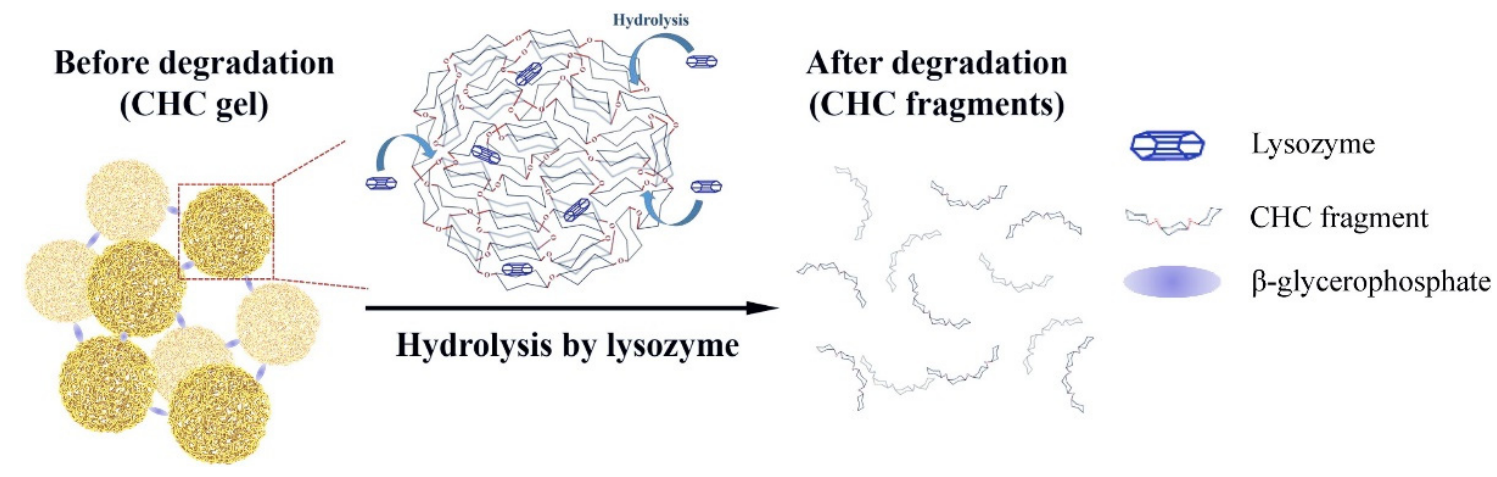

Figure 6. Illustration of lysozyme-dependent CHC gel degradation and insulin release. Adapted with permission from [48]; Published by Elsevier, 2016.

The in vivo application of a nanogel-based insulin delivery systems was explored by Wu et al. employing poly (3-acrylamidophenyl boronic acid), poly ( $N$-isopropylacrylamide), and dextran polymers in the synthesis of a nanogel. Subcutaneous injections of the MG3 insulin-loaded nanogel (4 IU kg/BW) as well as native insulin at a dose of $2.5 \mathrm{IU} \mathrm{kg} / \mathrm{BW}$ were administered to T1D rodents. The nanogel with a self-regulating $150 \mathrm{~nm}$ range was responsive to high blood glucose levels, and its swelling resulted in insulin release. In vivo animal studies revealed increased efficacy in controlling blood glucose levels for $2 \mathrm{~h}$ [49].

Lee et al. synthesized a glucose-responsive nanogel loaded with insulin by employing sodium alginate poly (L-glutmate-co- $N$-3-L-glutamylphenylboronic acid) and glycol $\mathrm{CHC}$ to synthesize a double-layered nanogel. In vitro cytotoxic assays and in vivo results demonstrated that the nanogel was biocompatible and glucose responsiveness was achieved [50].

\section{Stimuli-Responsive Hydrogels for Controlled Insulin Delivery}

Hydrogels containing glucose sensing carriers that trigger insulin release are designed to respond to varying blood glucose levels [58]. Switchable sol-gel transitions are triggered by stimuli-sensitive hydrogels with properties that facilitate a response to changes in their environment [59]. External factors that cause transitions in state can be physical, chemical, or biological. Stimuli-responsive hydrogels react to small changes in environmental variables that can include light, temperature, ionic strength, $\mathrm{pH}$, electrical, and magnetic fields [60,61]. Among stimuli-responsive triggers, $\mathrm{pH}$ and temperature responsiveness have received much attention due to their human physiological relevance and can be 
regulated and assayed under both in vitro and in vivo settings [35,62]. Stimuli-responsive hydrogels can also control the release of bioactives in response to specific triggers [63]. They can be synthesized by combining stimuli-responsive polymers such as alginate (enzymatic, ionic concentration), $\mathrm{CHC}$ ( $\mathrm{pH}$, enzymatic), poly( $\mathrm{N}$-isopropylacrylamide), pluronics (temperature), and others. Pluronic or poloxamer is a synthetic polymer that takes the form of a gel at high temperatures. Due to hydrophobic interactions, pluronic is a liquid while at cold temperatures. Due to the hydroxyl functional groups at the ends of the chain, chemical changes may easily take place. This synthetic polymer demonstrates gel integrity with extended incubation. This is advantageous for the long-term delivery of drugs, as it allows for sustained drug release [64]. These responsive polymers react rapidly to stimuli, resulting in structural modifications such as form or characteristics, solubility, and sol-gel transitioning in a reversible or irreversible manner [5]. Glucose-sensitive hydrogels have also been studied based on their desirable prospects for developing insulin delivery systems that can function as an artificial pancreas and delivering a precise quantity of insulin in response to blood glucose concentrations [35].

\subsection{Glucose Oxidase Stimuli Release Systems}

Glucose-responsive systems release bioactives proportionally to blood glucose concentration. When glucose oxidase (GOx) is coupled with $\mathrm{pH}$-responsive polymers such as $\mathrm{CHC}$, the enzymatic oxidation of glucose to gluconic acid catalyzed by GOx in the glucose solution causes the $\mathrm{pH}$ of the microenvironment to alter. Then, the $\mathrm{pH}$ shift causes the GOx-incorporated hydrogel to expand or shrink. When glucose is changed to gluconic acid by GOx while in the presence of $\mathrm{O}_{2}$, the local $\mathrm{pH}$ of the system drops, increasing the swelling of cationic hydrogels and releasing insulin. GOx has been covalently bonded onto a hydrogel to decrease the burst release of insulin in the system and promote the regulated loading of insulin [9].

Wang et al. created a degradable cross-linked gel, core-shell microneedle array patch for smart insulin administration coupled with a quick response and great biocompatibility. Figure 7 depicts a graphical representation of the stimuli responsive system. The hydrogel system partially dissolves and then releases insulin when stimulated by hydrogen peroxide $\left(\mathrm{H}_{2} \mathrm{O}_{2}\right) \cdot \mathrm{H}_{2} \mathrm{O}_{2}$ is produced during the oxidation of glucose by a glucose-specific enzyme covalently bonded inside the gel. Moreover, the microneedles, which are $\mathrm{H}_{2} \mathrm{O}_{2}$-responsive, are covered with a thin film carrying an $\mathrm{H}_{2} \mathrm{O}_{2}$-scavenging enzyme, imitating the complimentary role of peroxisome enzymes in protecting normal tissues from injury via oxidative stress. The researchers demonstrated in a T1D model that the formulated smart insulin patch with a protective shell and bioresponsive core could maintain normoglycemia with improved biocompatibility. The core-shell gelated MN array patch is suitable for glucosestimuli smart insulin delivery. The MN gels were made utilizing a "solution-gelation" process that involved the layering of diluted solution [65].

Figure 8 depicts the injectable nanonetwork of Gu et al. comprised of dextran nanoparticles. The acidic environment damaged the nanonetworks, which then were encapsulated with insulin, catalase, and GOx. Hyperglycemia causes the insulin to dissociate and release at the same time. To create a porous nanonetwork, alginate and $\mathrm{CHC}$ were utilized to coat acid-sensitive dextran to produce positively and negatively charged particles. In the presence of high BG levels, GOx converts glucose to gluconic acid, causing a $\mathrm{pH}$ shift and the release of insulin. This nanotech method was proven in vitro, demonstrating that a single injection maintained homeostatic glucose management $(<200 \mathrm{mg} / \mathrm{dL})$ for over a week in T1D mice when delivered subcutaneously within a degradable nano-network [66].

An interesting study carried out in North Carolina, USA demonstrated the use of ketal-modified dextran nanoparticles integrated within a hyaluronic acid microgel. The nanoparticles were glucose responsive by encapsulating GOx and insulin. The results from this study demonstrated an insulin release corresponding to changes in glucose levels in vitro. Animal studies were also carried out in STZ-induced T1D mice. Data showed a 
negligible toxicity and that a single subcutaneous injection maintained the normoglycemic state for over 7 days [67].

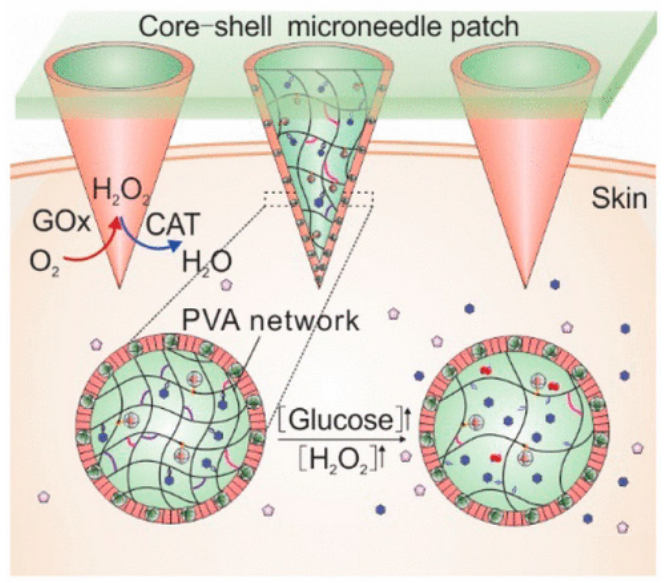

Figure 7. Mechanism of glucose-stimulated insulin release via glucose oxidase in a microneedle array patch. Adapted with permission from [65]; Published by ACS Nano, 2018.

(a)

(b)
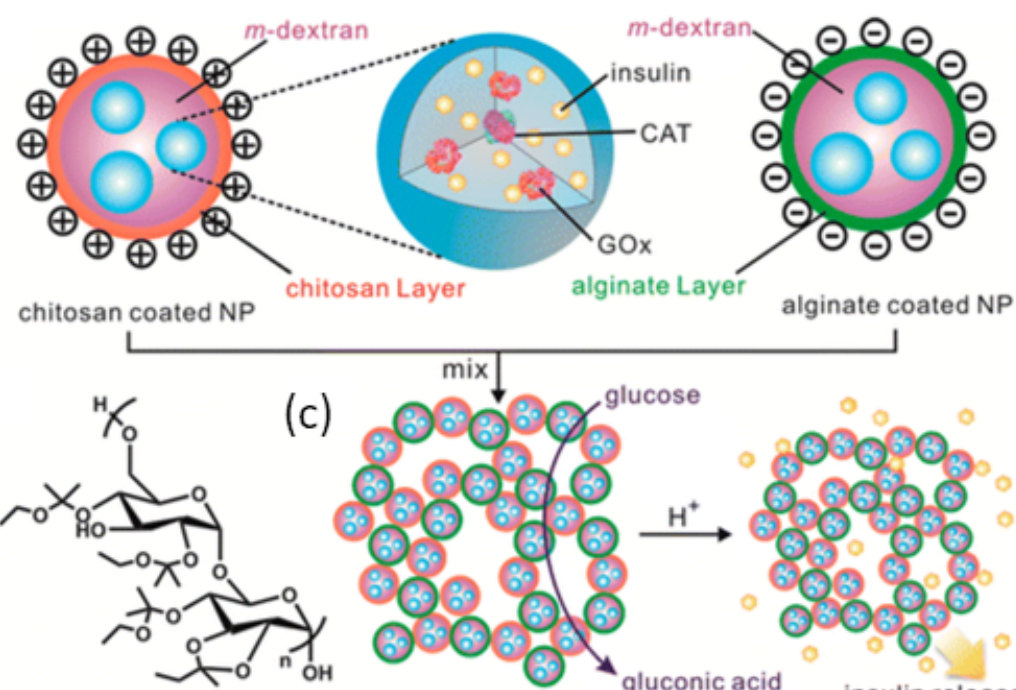

m-dextran

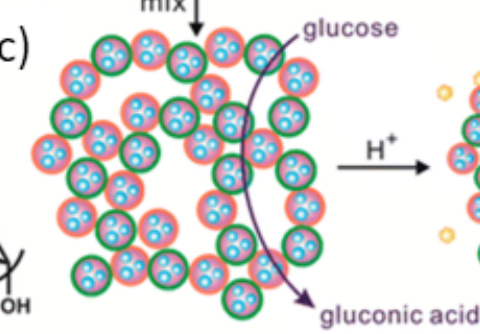

nano-network (NN)

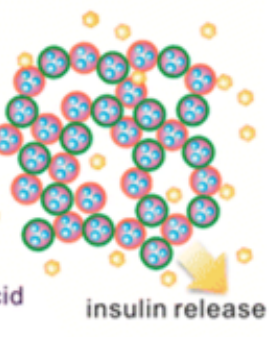

(d)
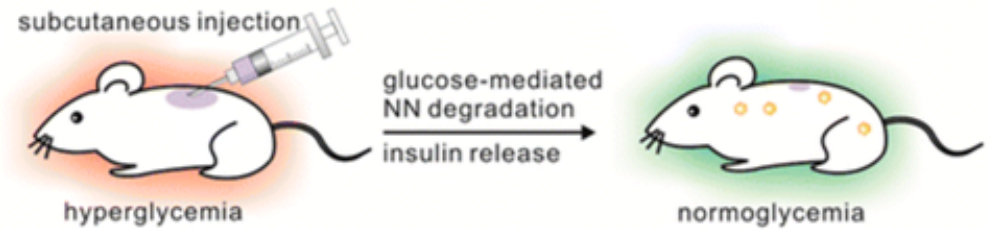

Figure 8. (a) Polymeric NPs functionalized with glucose-specific enzymes, CAT and GOx, and insulin. (b) m-dextran coated with CHC and alginate, respectively. (c) Depiction of the nano-network and stimulated insulin release via GOx conversion to gluconic acid. (d) SC insulin delivery for the treatment of DM in STZ-induced T1D mice. Adapted with permission from [66]; Published by ACS Nano, 2013.

$\mathrm{Li}$ et al. created a pH-sensitive peptide hydrogel to transport insulin, Gox, and catalase. Under physiological conditions, the peptide was able to self-assemble into a hydrogel. As there was an increase in blood glucose and the $\mathrm{pH}$ of the system decreased, insulin was released via deconstruction of the peptide hydrogel. On the contrary, as blood glucose levels fell and $\mathrm{pH}$ increased, the peptide hydrogels were able to reassemble, stopping the 
release of insulin while $\mathrm{GOx}$ regulated the local $\mathrm{pH}$. At a low enough $\mathrm{pH}$, the electrostatic repulsion between the charged lysine/ornithine side groups resulted in the unfolding of hairpins. As these peptide hydrogels effectively demonstrated control of blood glucose, they were considered promising biomaterials for diabetes therapy. Experiments in vivo demonstrated the hydrogel was injectable, biocompatible, and efficient in regulating blood glucose over time [68].

\subsection{Glucose-Responsive Stimuli Release Systems}

Concanavalin A (ConA) is derived from the jack bean plant and is a non-sugar protein. ConA has a highly reversible affinity for unmodified hydroxyl groups at carbons 3 to 4 and 6 of pyranose ring-containing glycopolymers, monosaccharides and polysaccharides, such -D-glucose [69]. The four molecules of ConA can form a tetramer complex with unaltered pyranose rings under physiological $\mathrm{pH}$. With a higher affinity for glucose than glycosylated polysaccharides and glycopolymers, ConA can be used to make glucosesensitive hydrogels, as shown in Figure $9[59,70]$. ConA binds to the hydrogel's glycosylated moieties, resulting in a highly complexed matrix with small pore diameters that trap insulin within the hydrogel. Glucose has a higher affinity for ConA than glycosylated moieties; therefore, glucose is able to displace the glycosylated polymer, resulting in the hydrogel either swelling and releasing insulin via diffusion or exhibiting a gel-sol transition and releasing insulin via matrix liberation [58].
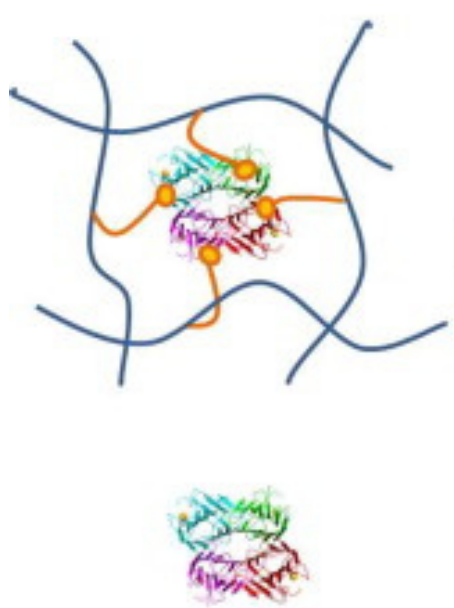

Concanavalin A
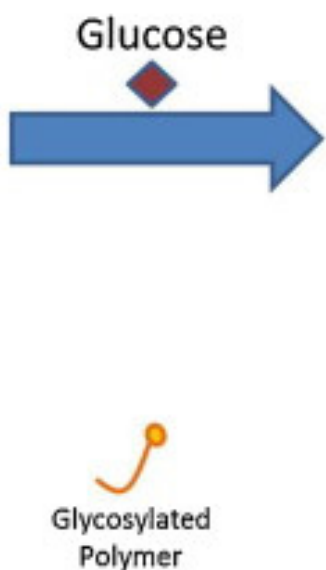

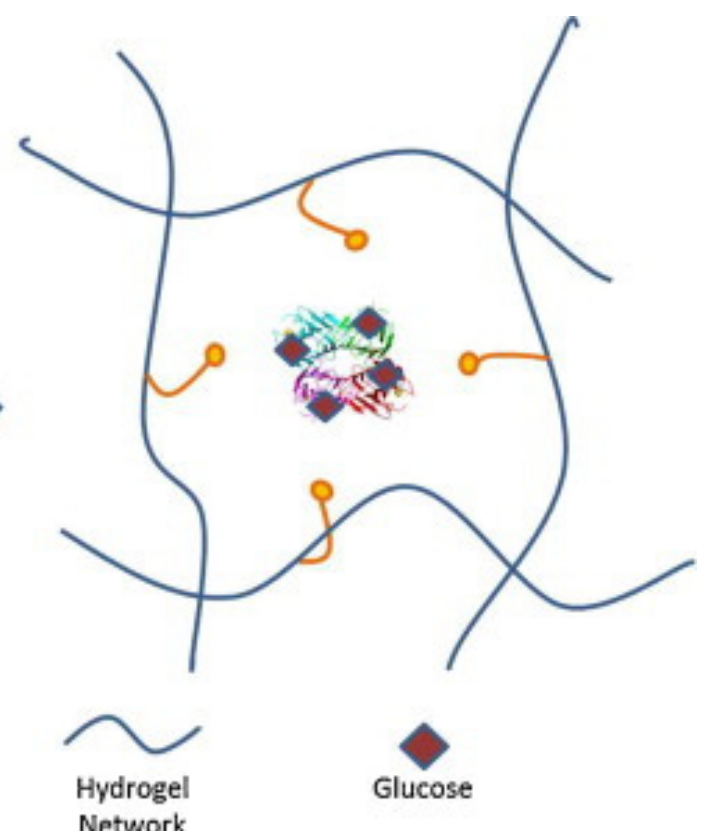

Network

Figure 9. Illustration of hydrogel network swelling for insulin release via ConA's affinity for glucose. Adapted with permission from [58]; Published by Elsevier, 2015.

ConA, on the other hand, may leak from a low viscosity sol, resulting in decreased glucose sensitivity as well as adverse cytotoxicity and immunogenicity. To circumvent these limitations, ConA has been used in combination with polymers to synthesize chemically cross-linked hydrogels. For example, Taylor et al. created a closed-loop system via a cross-linked ConA-dextran hydrogel for the administration of insulin. The hydrogel demonstrated real-time glucose sensitivity within an implantable artificial pancreas in a diabetic domestic pig [71].

In a pullulan-based glucose responsive hydrogel with a linear glucan structure, the possibility of intelligently regulated insulin release in proportion to fluctuations in blood glucose was examined. Figure 10A depicts the formation of a modified pullulan having 
- $\mathrm{COOH}$ groups (CPUL). A hydrogel comprising of covalently altered carboxylated pullulan and ConA (ConA-CPUL) was produced to limit ConA leakage by activating it with 1-ethyl3-(3-dimethylaminopropyl) carbodiimide/N-hydroxysuccinimide (EDC/NHS). Figure 10B shows the ConA-CPUL (insulin/ConA-CPUL) insulin-loaded hydrogel and glucose responsiveness via smart regulated insulin release in vitro. Studies carried out in vitro to determine drug release profiles revealed that the smart controlled release of insulin from the drug-loaded hydrogels was possible due to ConA-glucose binding. The viscoelasticity and shear thinning characteristics of covalently altered hydrogels were observed in the insulin/CPUL-ConA hydrogel. SEM images revealed a cross-linked network topologies with homogeneous porosity and insulin particles. As a result, this mechanism can provide glucose-responsive insulin release [72].

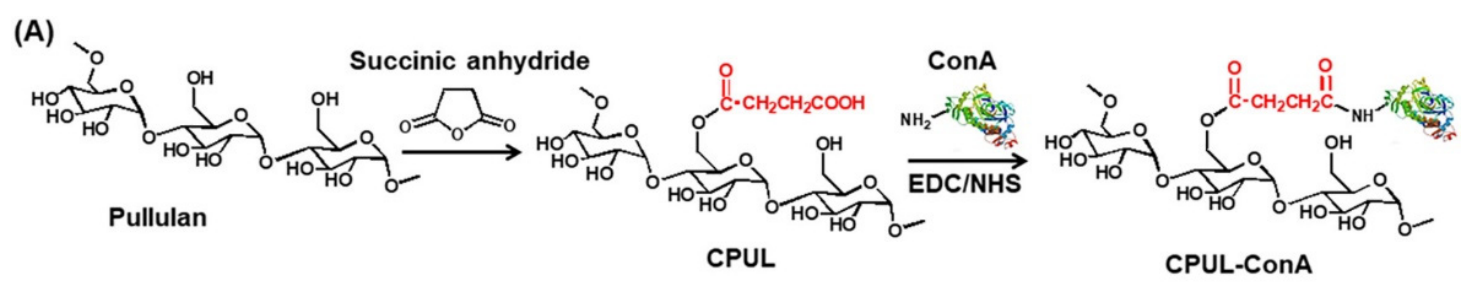

(B)

(a)

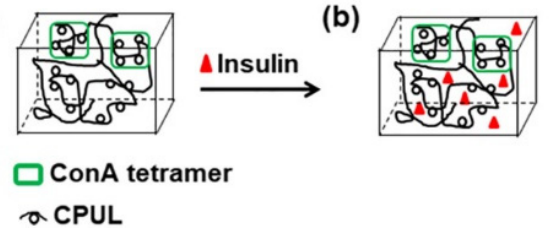

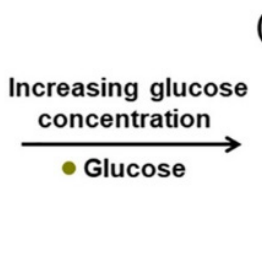

(c)

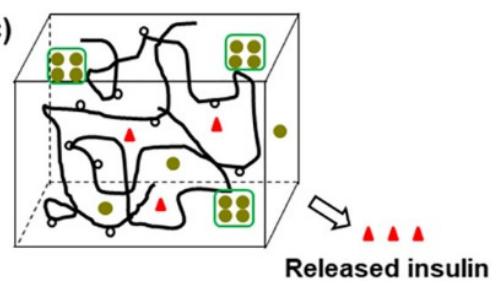

Figure 10. (A) Preparation of the CPUL-ConA hydrogel via EDC/NHS crosslinking. (B) Mechanism of controlled release of insulin from the CPUL-ConA hydrogel. (a) The ConA tetramer with the carboxylated Pullulan hydrogel. (b) Insulin drug added to the ConA-CPUL hydrogel. (c) Increasing glucose concentration in hydrogel environment demonstrating glucose responsiveness. Adapted with permission from [72]; Published by Elsevier, 2019.

Yin et al. used reversed-phase emulsion crosslinking to create glucose-sensitive microgels to determine if genipin-crosslinked ConA/GEA-CHC microgels may be employed as a glucose-sensitive DDS. In this work, the ConA polymer ligand was produced as a glucosyloxyethyl acrylated $\mathrm{CHC}$ derivative (GEA-CHC) that could be quickly crosslinked with ConA by genepin, avoiding ConA alteration during the immobilization process. In vitro analysis revealed that the microgels were non-toxic and that the released insulin remained active without altering its tertiary structure. ConA leakage was also limited as a result of genepin crosslinking [69].

\subsection{Temperature/Thermo-Responsive Stimuli Release of Insulin}

The structure of thermo-responsive hydrogels has a hydrophobic-hydrophilic balance. The collapse or relaxation of the hydrogel chain occurs when the temperature changes near the critical solution temperature (CST). This is in reaction to changes in the hydrophilic and hydrophobic interactions between hydrogel polymer chains and water molecules. The temperature at which the polymer solution divides from one phase to two phases is referred to as the CST [73]. Temperature-sensitive hydrogels have the capacity to swell/deswell in response to environmental temperature variations [62]. This characteristic is heavily influenced by the upper (UCST) or lower critical solution temperature (LCST). Dehydration occurs in the UCST when the ambient temperature is below the LCST (i.e., it is soluble at higher temperatures), but deswelling occurs when the ambient temperature is above the LCST (i.e., it is soluble at lower temperature). Since the polymer solution may undergo thermally induced self-assembly (post injecting) to form a hydrogel at $37^{\circ} \mathrm{C}$, polymers 
with an LCST/phase transition between ambient temperature and $37^{\circ} \mathrm{C}$ have been used to synthesize injectable in situ hydrogels [74].

Lee et al. used pentablock copolymers to produce a hybrid thermo-responsive platform for insulin delivery. The copolymers used were oligomer serin-b-poly (lactide)-bpoly (ethylene glycol)-b-poly (lactide)-b-oligomer serine (OS-PLA-PEG-PLA-OS). They developed nanospheres were uniformly dispersed throughout the matrix, reinforcing the mechanical characteristics of the hydrogel depot and prolonging its degradation period under physiological circumstances. To assess the in vitro insulin-release profile, the hydrogel-nanosphere system was subcutaneously injected into diabetic BALB/c rodents. The results demonstrated that the concentration of insulin in the blood remained steady. The insulin's bio-property was preserved and demonstrated blood glucose lowering for longer than $60 \mathrm{~h}$ post administration into a streptozotocin (STZ)-induced diabetic rodent model. This indicates that the injectable $\mathrm{pH}$-temperature sensitive hydrogel containing $\mathrm{CHC}$-insulin electrosprayed nanosphere composites has promising potential applications for T1D therapy [75].

\subsection{Metal-Conjugated Platforms for Potential Insulin Delivery}

Hydrogels that are sensitive to electric and magnetic fields modify their characteristics stimuli responsively to minor variations in electric current or external fields. These systems have been studied as swellable, shrinkable, and bendable hydrogels. These hydrogels have been extensively researched as polyelectrolyte hydrogels (systems that contain a high concentration of ionizable) [76]. Polyvinyl alcohol, acrylic acid/vinyl sulfonic acid, and sulfonated polystyrene are some of the synthetic polymers utilized to produce electroactive hydrogels. Natural polymers are also often used in the fabrication of electro- and magnetically sensitive devices. Hyaluronic acid, alginate, and $\mathrm{CHC}$, for example, have been used in combination with synthetic polymers to create electroactive hydrogels $[35,76]$.

\section{The Use of 3D Bio-Printing to Engineer an Artificial Pancreas and Other 21st Century Techniques}

The idealized solution to the diabetes mellitus pandemic would be islet and pancreatic transplantation for endogenous insulin release. However, the transplantations are plagued with problems. Diabetic patients have to undergo surgery, which is only possible if organs are readily available, and thereafter, the individual will be on chronic immunosuppression, which is not ideal as T1D often manifests in children [77]. Thus, the introduction of 3D printing in the biological field opened the doors to the regeneration and replacement of biological tissue and organs (bioimplants) for the development of the artificial pancreas [78]. This is important, as the printed scaffold can be placed at the targeted site where tissue regeneration/organ replacement can take place. Both natural and synthetic polymers as well as bioinks, which are living cells contained within a cellular matric, are used in 3D bioprinting [78].

As the treatment of T1D results in poor patient compliance and unwanted side effects, in 2019, researchers (Kim et al., 2019) strived to develop a system that could potentially regenerate pancreatic $\beta$-cell function. They synthesized a pancreatic tissue-derived extracellular matrix bioink, and using both child and adult islet cells, they were able to validate that the bioink fulfilled the criterion for tissue engineering and could work as a 3D construct [79].

Three-dimensional (3D) printing may take place via inkjet, laser printing, stereolithography, or via extrusion [77]. The extrusion method of 3D printing was carried out by Duin et al. to formulate a methylcellulose/alginate hydrogel loaded with pancreatic islets. The data showed that the islets were still able to produce insulin and glucagon and demonstrated slight glucose responsiveness. The researchers loaded the islet tissue within a hydrogel to protect it from physiological degradation within the body; this was confirmed when the morphology and $\alpha$ and $\beta$ cells within the islets were maintained [80].

However, as with emerging technology, there are challenges that need to be addressed. The time taken to construct the material, the management of cell viability, and crucially the 
biocompatible materials for synthesis, which can be very costly, are some of the limitations to 3D bioprinting [78].

\section{Future Perspectives}

Emerging insulin administration techniques have the potential to dramatically improve patient compliance to achieve glycemic control and improved quality of life and delay/reduce risk of complications and death. Smart insulin delivery systems that respond to external stimuli and adapt to individual physiological circumstances to provide regulated insulin release are at the forefront of T1D treatment research. The design, synthesis, characteristics, and use of smart hydrogels in biomedical engineering have undergone a paradigm shift in the last decade [35]. As extensively outlined by Kondiah et al., various stimuli systems have been evaluated for various controlled release kinetics as well as rapid release systems, encapsulating proteins of various nature, as well as tissue engineered delivery systems for optimal therapeutic efficacy for future applications [81]. Islet-loaded hydrogels are a promising area for the possible regeneration of T1D $\beta$-cells. As a result, regenerative medicine and tissue engineering are inextricably linked with the controlled delivery of insulin [8]. Islet transplantation has been performed in over 1500 patients. However, many hurdles remain such as immunotherapy, a lack of donors, and importantly, researchers are yet not able to reproduce the microenvironment conditions of the islet cells [82]. Although considerable progress has been made, the practical application of hydrogels is limited by the issues of complex production process and high cost. Therefore, an ideal prolonged delivery system for insulin overcoming the mentioned issues is still required [4]. However, with a greater understanding of local environmental circumstances, cellular and metabolic processes in the healthy and pathologic states, and the chemicals available for the creation of injectable hydrogels, the administration of diabetic treatment can easily be transferred from research to clinical reality. As a result, the utilization of injectable systems for therapeutic administration is seen to have considerable promise [6].

\section{Conclusions}

To adapt to physiological changes, stimuli-responsive hydrogels have been synthesized. When specialized, they become particularly appealing for various biological applications due to their unique properties of controlled swelling, biocompatibility, biodegradability, and preserving fluid within their networked structures. Injectable hydrogels can enhance the controlled distribution and prolonged release of insulin in both systemic and localized settings. Hydrogels can be used for patient-centric advances to be made in insulin delivery by offering spatio-temporal control over the administered insulin. Modified hydrogels as smart systems can satisfy a key requirement in controlled injectable insulin delivery based on their chemical composition and method of synthesis. The fundamental paradox in the use of mechanical characteristics of hydrogels for controlled insulin delivery is that increasing the polymer concentration increases the mechanical strength at the expense of poor biocompatibility and biodegradability. A therapeutically appropriate design for oral insulin has not yet been proven successful; however, attempts are still being made in this area. The next generation of smart insulin delivery systems should impress rapid response, simplicity of preparation and administration, and high biocompatibility. Thus, injectable 'smart' hydrogels remain the forerunner for the development of advanced patient-centric therapy for T1D. Further in vivo testing of the response to varied glucose levels is required before clinical translation of the various technologies.

Funding: This research was funded by the National Research Foundation (N.R.F.) of South Africa.

Institutional Review Board Statement: Not applicable.

Informed Consent Statement: Not applicable.

Data Availability Statement: Not applicable.

Acknowledgments: We would like to acknowledge the N.R.F. for supporting this research project. 
Conflicts of Interest: The authors declare no conflict of interest.

\section{References}

1. DeFronzo, R.A. Pathogenesis of Type 2 Diabetes Mellitus. In Diabetes Epidemiology, Genetics, Pathogenesis, Diagnosis, Prevention, and Treatment; Bonora, E., DeFronzo, R.A., Eds.; Springer International Publishing: Cham, Switzerland, 2018; pp. 181-253. [CrossRef]

2. Sarbacker, G.B.; Urteaga, E.M. Adherence to insulin therapy. Diabetes Spectr. 2016, 29, 166-170. [CrossRef]

3. Wagner, A.M.; Gran, M.P.; Peppas, N.A. Designing the new generation of intelligent biocompatible carriers for protein and peptide delivery. Acta Pharm. Sin. B 2018, 8, 147-164. [CrossRef]

4. Zhang, T.; Luo, J.; Peng, Q.; Dong, J.; Wang, Y.; Gong, T.; Zhang, Z. Injectable and biodegradable phospholipid-based phase separation gel for sustained delivery of insulin. Colloids Surf. B Biointerfaces 2019, 176, 194-201. [CrossRef] [PubMed]

5. Mathew, A.P.; Cho, K.-H.; Uthaman, S.; Cho, C.-S.; Park, I.-K. Stimuli-regulated smart polymeric systems for gene therapy. Polymers 2017, 9, 152. [CrossRef] [PubMed]

6. Mathew, A.P.; Uthaman, S.; Cho, K.-H.; Cho, C.-S.; Park, I.-K. Injectable hydrogels for delivering biotherapeutic molecules. Int. J. Biol. Macromol. 2018, 110, 17-29. [CrossRef] [PubMed]

7. Chen, G.; Tang, W.; Wang, X.; Zhao, X.; Chen, C.; Zhu, Z. Applications of Hydrogels with Special Physical Properties in Biomedicine. Polymers 2019, 11, 1420. [CrossRef]

8. Chai, Q.; Jiao, Y.; Yu, X. Hydrogels for biomedical applications: Their characteristics and the mechanisms behind them. Gels 2017, 3, 6. [CrossRef] [PubMed]

9. Ullah, F.; Othman, M.B.H.; Javed, F.; Ahmad, Z.; Akil, H.M. Classification, processing and application of hydrogels: A review. Mater. Sci. Eng. C 2015, 57, 414-433. [CrossRef]

10. Singhal, R.; Gupta, K. A review: Tailor-made hydrogel structures (classifications and synthesis parameters). Polym.-Plast. Technol. Eng. 2016, 55, 54-70. [CrossRef]

11. Ahmed, E.M. Hydrogel: Preparation, characterization, and applications: A review. J. Adv. Res. 2015, 6, 105-121. [CrossRef]

12. Li, J.; Mooney, D.J. Designing hydrogels for controlled drug delivery. Nat. Rev. Mater. 2016, 1, 10671. [CrossRef] [PubMed]

13. Kumar, A.; Vimal, A.; Kumar, A. Why Chitosan? From properties to perspective of mucosal drug delivery. Int. J. Biol. Macromol. 2016, 91, 615-622. [CrossRef] [PubMed]

14. Brown, T.D.; Whitehead, K.A.; Mitragotri, S. Materials for oral delivery of proteins and peptides. Nat. Rev. Mater. 2020, 5, 127-148. [CrossRef]

15. Muheem, A.; Shakeel, F.; Jahangir, M.A.; Anwar, M.; Mallick, N.; Jain, G.K.; Warsi, M.H.; Ahmad, F.J. A review on the strategies for oral delivery of proteins and peptides and their clinical perspectives. Saudi Pharm. J. 2016, 24, 413-428. [CrossRef]

16. Deb, P.K.; Al-Attraqchi, O.; Chandrasekaran, B.; Paradkar, A.; Tekade, R.K. Protein/peptide drug delivery systems: Practical considerations in pharmaceutical product development. In Basic Fundamentals of Drug Delivery; Elsevier: Amsterdam, The Netherlands, 2019; pp. 651-684.

17. Doostmohammadi, M.; Ameri, A.; Mohammadinejad, R.; Dehghannoudeh, N.; Banat, I.M.; Ohadi, M.; Dehghannoudeh, G. Hydrogels For Peptide Hormones Delivery: Therapeutic And Tissue Engineering Applications. Drug Des. Dev. Ther. 2019, 13, 3405. [CrossRef]

18. Akhtar, M.F.; Hanif, M.; Ranjha, N.M. Methods of synthesis of hydrogels ... A review. Saudi Pharm. J. 2016, $24,554-559$. [CrossRef]

19. Hu, J.; Chen, Y.; Li, Y.; Zhou, Z.; Cheng, Y. A thermo-degradable hydrogel with light-tunable degradation and drug release. Biomaterials 2017, 112, 133-140. [CrossRef] [PubMed]

20. Stanislawska, I.; Liwinska, W.; Lyp, M.; Stojek, Z.; Zabost, E. Recent Advances in Degradable Hybrids of Biomolecules and NGs for Targeted Delivery. Molecules 2019, 24, 1873. [CrossRef]

21. Kondiah, P.P.; Choonara, Y.E.; Tomar, L.K.; Tyagi, C.; Kumar, P.; du Toit, L.C.; Marimuthu, T.; Modi, G.; Pillay, V. Development of a gastric absorptive, immediate responsive, oral protein-loaded versatile polymeric delivery system. AAPS PharmSciTech 2017, 18, 2479-2493. [CrossRef]

22. Matsumoto, N.M.; González-Toro, D.C.; Chacko, R.T.; Maynard, H.D.; Thayumanavan, S. Synthesis of nanogel-protein conjugates. Polym. Chem. 2013, 4, 2464-2469. [CrossRef]

23. Chen, W.; Zheng, M.; Meng, F.; Cheng, R.; Deng, C.; Feijen, J.; Zhong, Z. In situ forming reduction-sensitive degradable nanogels for facile loading and triggered intracellular release of proteins. Biomacromolecules 2013, 14, 1214-1222. [CrossRef] [PubMed]

24. Wang, Y.; Xu, S.; Xiong, W.; Pei, Y.; Li, B.; Chen, Y. Nanogels fabricated from bovine serum albumin and chitosan via self-assembly for delivery of anticancer drug. Colloids Surf. B Biointerfaces 2016, 146, 107-113. [CrossRef] [PubMed]

25. Nukolova, N.V.; Oberoi, H.S.; Cohen, S.M.; Kabanov, A.V.; Bronich, T.K. Folate-decorated nanogels for targeted therapy of ovarian cancer. Biomaterials 2011, 32, 5417-5426. [CrossRef] [PubMed]

26. Aoki, M.; Ueda, S.; Nishikawa, H.; Kitano, S.; Hirayama, M.; Ikeda, H.; Toyoda, H.; Tanaka, K.; Kanai, M.; Takabayashi, A. Antibody responses against NY-ESO-1 and HER2 antigens in patients vaccinated with combinations of cholesteryl pullulan (CHP)-NY-ESO-1 and CHP-HER2 with OK-432. Vaccine 2009, 27, 6854-6861. [CrossRef] [PubMed]

27. Nuhn, L.; Vanparijs, N.; De Beuckelaer, A.; Lybaert, L.; Verstraete, G.; Deswarte, K.; Lienenklaus, S.; Shukla, N.M.; Salyer, A.C.; Lambrecht, B.N. pH-degradable imidazoquinoline-ligated nanogels for lymph node-focused immune activation. Proc. Natl. Acad. Sci. USA 2016, 113, 8098-8103. [CrossRef] 
28. Park, J.S.; Yi, S.W.; Kim, H.J.; Park, K.-H. Receptor-mediated gene delivery into human mesenchymal stem cells using hyaluronic acid-shielded polyethylenimine/pDNA nanogels. Carbohydr. Polym. 2016, 136, 791-802. [CrossRef]

29. Chen, J.; Ding, J.; Wang, Y.; Cheng, J.; Ji, S.; Zhuang, X.; Chen, X. Sequentially responsive shell-stacked nanoparticles for deep penetration into solid tumors. Adv. Mater. 2017, 29, 1701170. [CrossRef] [PubMed]

30. Zhang, Y.; Wang, F.; Li, M.; Yu, Z.; Qi, R.; Ding, J.; Zhang, Z.; Chen, X. Self-Stabilized Hyaluronate Nanogel for Intracellular Codelivery of Doxorubicin and Cisplatin to Osteosarcoma. Adv. Sci. 2018, 5, 1700821. [CrossRef]

31. Gao, X.; Cao, Y.; Song, X.; Zhang, Z.; Zhuang, X.; He, C.; Chen, X. Biodegradable, pH-Responsive Carboxymethyl Cellulose/Poly(Acrylic Acid) Hydrogels for Oral Insulin Delivery. Macromol. Biosci. 2014, 14, 565-575. [CrossRef]

32. Yang, Y.; Liu, Y.; Chen, S.; Cheong, K.-L.; Teng, B. Carboxymethyl $\beta$-cyclodextrin grafted carboxymethyl chitosan hydrogel-based microparticles for oral insulin delivery. Carbohydr. Polym. 2020, 246, 116617. [CrossRef]

33. Park, M.J.; Hur, S.M.; Rhee, H.K. Online estimation and control of polymer quality in a copolymerization reactor. AIChE J. 2002, 48, 1013-1021. [CrossRef]

34. Peppas, N.; Bures, P.; Leobandung, W.; Ichikawa, H. Hydrogels in pharmaceutical formulations. Eur. J. Pharm. Biopharm. 2000, 50, 27-46. [CrossRef]

35. Mantha, S.; Pillai, S.; Khayambashi, P.; Upadhyay, A.; Zhang, Y.; Tao, O.; Pham, H.M.; Tran, S.D. Smart Hydrogels in Tissue Engineering and Regenerative Medicine. Materials 2019, 12, 3323. [CrossRef]

36. Kondiah, P.P.; Tomar, L.K.; Tyagi, C.; Choonara, Y.E.; Modi, G.; du Toit, L.C.; Kumar, P.; Pillay, V. A novel pH-sensitive interferon- $\beta$ (INF- $\beta$ ) oral delivery system for application in multiple sclerosis. Int. J. Pharm. 2013, 456, 459-472. [CrossRef]

37. Chirani, N.; Gritsch, L.; Motta, F.L.; Fare, S. History and applications of hydrogels. J. Biomed. Sci. 2015, 4. [CrossRef]

38. Gupta, P.; Vermani, K.; Garg, S. Hydrogels: From controlled release to pH-responsive drug delivery. Drug Discov. Today 2002, 7, 569-579. [CrossRef]

39. Cuggino, J.C.; Blanco, E.R.O.; Gugliotta, L.M.; Igarzabal, C.I.A.; Calderón, M. Crossing biological barriers with nanogels to improve drug delivery performance. J. Control. Release 2019, 307, 221-246. [CrossRef] [PubMed]

40. Xue, K. Injectable Supramolecular Hydrogels for Insulin Delivery; Massachusetts Institute of Technology: Boston, MA, USA, 2017.

41. Dong, Y.; Wang, W.; Veiseh, O.; Appel, E.A.; Xue, K.; Webber, M.J.; Tang, B.C.; Yang, X.-W.; Weir, G.C.; Langer, R.; et al. Injectable and Glucose-Responsive Hydrogels Based on Boronic Acid-Glucose Complexation. Langmuir 2016, 32, 8743-8747. [CrossRef]

42. Zhao, F.; Wu, D.; Yao, D.; Guo, R.; Wang, W.; Dong, A.; Kong, D.; Zhang, J. An injectable particle-hydrogel hybrid system for glucose-regulatory insulin delivery. Acta Biomater. 2017, 64, 334-345. [CrossRef]

43. Lee, J.; Ko, J.H.; Mansfield, K.M.; Nauka, P.C.; Bat, E.; Maynard, H.D. Glucose-Responsive Trehalose Hydrogel for Insulin Stabilization and Delivery. Macromol. Biosci. 2018, 18, e1700372. [CrossRef]

44. Maity, B.; Samanta, S.; Sarkar, S.; Alam, S.; Govindaraju, T. Injectable Silk Fibroin-Based Hydrogel for Sustained Insulin Delivery in Diabetic Rats. ACS Appl. Bio Mater. 2020, 3, 3544-3552. [CrossRef]

45. Volpatti, L.R.; Facklam, A.L.; Cortinas, A.B.; Lu, Y.-C.; Matranga, M.A.; MacIsaac, C.; Hill, M.C.; Langer, R.; Anderson, D.G. Microgel encapsulated nanoparticles for glucose-responsive insulin delivery. Biomaterials 2021, 267, 120458. [CrossRef] [PubMed]

46. Wang, L.-Y.; Gu, Y.-H.; Zhou, Q.-Z.; Ma, G.-H.; Wan, Y.-H.; Su, Z.-G. Preparation and characterization of uniform-sized chitosan microspheres containing insulin by membrane emulsification and a two-step solidification process. Colloids Surf. B Biointerfaces 2006, 50, 126-135. [CrossRef]

47. Di, J.; Yu, J.; Wang, Q.; Yao, S.; Suo, D.; Ye, Y.; Pless, M.; Zhu, Y.; Jing, Y.; Gu, Z. Ultrasound-triggered noninvasive regulation of blood glucose levels using microgels integrated with insulin nanocapsules. Nano Res. 2017, 10, 1393-1402. [CrossRef]

48. Chou, H.-S.; Larsson, M.; Hsiao, M.-H.; Chen, Y.-C.; Röding, M.; Nydén, M.; Liu, D.-M. Injectable insulin-lysozyme-loaded nanogels with enzymatically-controlled degradation and release for basal insulin treatment: In vitro characterization and in vivo observation. J. Control. Release 2016, 224, 33-42. [CrossRef]

49. Wu, Z.; Zhang, X.; Guo, H.; Li, C.; Yu, D. An injectable and glucose-sensitive nanogel for controlled insulin release. J. Mater. Chem. 2012, 22, 22788-22796. [CrossRef]

50. Lee, D.; Choe, K.; Jeong, Y.; Yoo, J.; Lee, S.M.; Park, J.-H.; Kim, P.; Kim, Y.-C. Establishment of a controlled insulin delivery system using a glucose-responsive double-layered nanogel. RSC Adv. 2015, 5, 14482-14491. [CrossRef]

51. Suner, S.S.; Sahiner, M.; Sengel, S.B.; Rees, D.J.; Reed, W.F.; Sahiner, N. Responsive biopolymer-based microgels/nanogels for drug delivery applications. In Stimuli Responsive Polymeric Nanocarriers for Drug Delivery Applications; Elsevier: Amsterdam, The Netherlands, 2018; Volume 1, pp. 453-500.

52. Newsom, J.P.; Payne, K.A.; Krebs, M.D. Microgels: Modular, tunable constructs for tissue regeneration. Acta Biomater. 2019, 88, 32-41. [CrossRef] [PubMed]

53. Thomas, V.; Namdeo, M.; Murali Mohan, Y.; Bajpai, S.; Bajpai, M. Review on polymer, hydrogel and microgel metal nanocomposites: A facile nanotechnological approach. J. Macromol. Sci. Part A Pure Appl. Chem. 2007, 45, 107-119. [CrossRef]

54. Pepe, A.; Podesva, P.; Simone, G. Tunable uptake/release mechanism of protein microgel particles in biomimicking environment. Sci. Rep. 2017, 7, 6014. [CrossRef] [PubMed]

55. Neamtu, I.; Rusu, A.G.; Diaconu, A.; Nita, L.E.; Chiriac, A.P. Basic concepts and recent advances in nanogels as carriers for medical applications. Drug Deliv. 2017, 24, 539-557. [CrossRef] [PubMed]

56. Hajebi, S.; Rabiee, N.; Bagherzadeh, M.; Ahmadi, S.; Rabiee, M.; Roghani-Mamaqani, H.; Tahriri, M.; Tayebi, L.; Hamblin, M.R. Stimulus-responsive polymeric nanogels as smart drug delivery systems. Acta Biomater. 2019, 92, 1-18. [CrossRef] 
57. Rahmanian-Devin, P.; Baradaran Rahimi, V.; Askari, V.R. Thermosensitive Chitosan- $\beta$-Glycerophosphate Hydrogels as Targeted Drug Delivery Systems: An Overview on Preparation and Their Applications. Adv. Pharmacol. Pharm. Sci. 2021, $2021,6640893$. [CrossRef]

58. Koetting, M.C.; Peters, J.T.; Steichen, S.D.; Peppas, N.A. Stimulus-responsive hydrogels: Theory, modern advances, and applications. Mater. Sci. Eng. R Rep. 2015, 93, 1-49. [CrossRef] [PubMed]

59. Willner, I. Stimuli-Controlled Hydrogels and Their Applications; ACS Publications: Washington, DC, USA, 2017.

60. Bukhari, S.M.H.; Khan, S.; Rehanullah, M.; Ranjha, N.M. Synthesis and characterization of chemically cross-linked acrylic acid/gelatin hydrogels: Effect of $\mathrm{pH}$ and composition on swelling and drug release. Int. J. Polym. Sci. 2015, 2015, 187961. [CrossRef]

61. Deen, G.R.; Loh, X.J. Stimuli-responsive cationic hydrogels in drug delivery applications. Gels 2018, 4, 13. [CrossRef]

62. Chaturvedi, K.; Ganguly, K.; Nadagouda, M.N.; Aminabhavi, T.M. Polymeric hydrogels for oral insulin delivery. J. Control. Release 2013, 165, 129-138. [CrossRef] [PubMed]

63. Wu, H.-Q.; Wang, C.-C. Biodegradable Smart Nanogels: A New Platform for Targeting Drug Delivery and Biomedical Diagnostics. Langmuir 2016, 32, 6211-6225. [CrossRef]

64. Bodratti, A.M.; Alexandridis, P. Formulation of poloxamers for drug delivery. J. Funct. Biomater. 2018, 9, 11. [CrossRef]

65. Wang, J.; Ye, Y.; Yu, J.; Kahkoska, A.R.; Zhang, X.; Wang, C.; Sun, W.; Corder, R.D.; Chen, Z.; Khan, S.A. Core-Shell Microneedle Gel for Self-Regulated Insulin Delivery. ACS Nano 2018, 12, 2466-2473. [CrossRef]

66. Gu, Z.; Aimetti, A.A.; Wang, Q.; Dang, T.T.; Zhang, Y.; Veiseh, O.; Cheng, H.; Langer, R.S.; Anderson, D.G. Injectable NanoNetwork for Glucose-Mediated Insulin Delivery. ACS Nano 2013, 7, 4194-4201. [CrossRef]

67. Di, J.; Yu, J.; Ye, Y.; Ranson, D.; Jindal, A.; Gu, Z. Engineering Synthetic Insulin-Secreting Cells Using Hyaluronic Acid Microgels Integrated with Glucose-Responsive Nanoparticles. Cell. Mol. Bioeng. 2015, 8, 445-454. [CrossRef]

68. Li, X.; Fu, M.; Wu, J.; Zhang, C.; Deng, X.; Dhinakar, A.; Huang, W.; Qian, H.; Ge, L. pH-sensitive peptide hydrogel for glucose-responsive insulin delivery. Acta Biomater. 2017, 51, 294-303. [CrossRef] [PubMed]

69. Yin, R.; Wang, K.; Du, S.; Chen, L.; Nie, J.; Zhang, W. Design of genipin-crosslinked microgels from concanavalin A and glucosyloxyethyl acrylated chitosan for glucose-responsive insulin delivery. Carbohydr. Polym. 2014, 103, 369-376. [CrossRef] [PubMed]

70. Chang, R.; Li, M.; Ge, S.; Yang, J.; Sun, Q.; Xiong, L. Glucose-responsive biopolymer nanoparticles prepared by co-assembly of concanavalin A and amylopectin for insulin delivery. Ind. Crop. Prod. 2018, 112, 98-104. [CrossRef]

71. Taylor, M.; Gregory, R.; Tomlins, P.; Jacob, D.; Hubble, J.; Sahota, T. Closed-loop glycaemic control using an implantable artificial pancreas in diabetic domestic pig (Sus scrofa domesticus). Int. J. Pharm. 2016, 500, 371-378. [CrossRef] [PubMed]

72. Lin, K.; Yi, J.; Mao, X.; Wu, H.; Zhang, L.-M.; Yang, L. Glucose-sensitive hydrogels from covalently modified carboxylated pullulan and concanavalin A for smart controlled release of insulin. React. Funct. Polym. 2019, 139, 112-119. [CrossRef]

73. Thambi, T.; Li, Y.; Lee, D.S. Injectable hydrogels for sustained release of therapeutic agents. J. Control. Release 2017, 267, 57-66. [CrossRef] [PubMed]

74. Kim, E.J.; Choi, J.S.; Kim, J.S.; Choi, Y.C.; Cho, Y.W. Injectable and Thermosensitive Soluble Extracellular Matrix and Methylcellulose Hydrogels for Stem Cell Delivery in Skin Wounds. Biomacromolecules 2016, 17, 4-11. [CrossRef]

75. Lee, D.S.; Huynh, D.P.; Thai Minh, D.L.; Trinh, T.A.; Ho, H.G.V.; To, T.C.T.; Nguyen, V.V.L. A Novel Injectable pH-Temperature Sensitive Hydrogel Contained Chitosan-Insulin Electrosprayed Nanospheres Composite For Insulin Delivery System In Type I Diabetes Treatment. Biomater. Sci. 2020, 8, 3830-3843. [CrossRef]

76. Ghadban, A.; Ahmed, A.S.; Ping, Y.; Ramos, R.; Arfin, N.; Cantaert, B.; Ramanujan, R.V.; Miserez, A. Bioinspired pH and magnetic responsive catechol-functionalized chitosan hydrogels with tunable elastic properties. Chem. Commun. 2016, 52, 697-700. [CrossRef] [PubMed]

77. Karzyński, K.; Kosowska, K.; Ambrożkiewicz, F.; Berman, A.; Cichoń, J.; Klak, M.; Serwańska-Świętek, M.; Wszoła, M. Use of 3D bioprinting in biomedical engineering for clinical application. Med. Stud. Studia Med. 2018, 34, 93-97. [CrossRef]

78. Vanaei, S.; Parizi, M.S.; Vanaei, S.; Salemizadehparizi, F.; Vanaei, H.R. An Overview on Materials and Techniques in 3D Bioprinting Toward Biomedical Application. Eng. Regen. 2021, 2, 1-18. [CrossRef]

79. Kim, J.; Shim, I.K.; Hwang, D.G.; Lee, Y.N.; Kim, M.; Kim, H.; Kim, S.-W.; Lee, S.; Kim, S.C.; Cho, D.-W.; et al. 3D cell printing of islet-laden pancreatic tissue-derived extracellular matrix bioink constructs for enhancing pancreatic functions. J. Mater. Chem. B 2019, 7, 1773-1781. [CrossRef] [PubMed]

80. Duin, S.; Schütz, K.; Ahlfeld, T.; Lehmann, S.; Lode, A.; Ludwig, B.; Gelinsky, M. 3D Bioprinting of Functional Islets of Langerhans in an Alginate/Methylcellulose Hydrogel Blend. Adv. Healthc. Mater. 2019, 8, 1801631. [CrossRef] [PubMed]

81. Kondiah, P.; Choonara, Y.; Kondiah, P.; Marimuthu, T.; Kumar, P.; du Toit, L.; Pillay, V. A review of injectable polymeric hydrogel systems for application in bone tissue engineering. Molecules 2016, 21, 1580. [CrossRef]

82. Espona-Noguera, A.; Ciriza, J.; Cañibano-Hernández, A.; Fernandez, L.; Ochoa, I.; Saenz del Burgo, L.; Pedraz, J.L. Tunable injectable alginate-based hydrogel for cell therapy in Type 1 Diabetes Mellitus. Int. J. Biol. Macromol. 2018, 107, 1261-1269. [CrossRef] 